\title{
Developing a Conceptual Framework for Evaluation of E-Content of Virtual Courses: E-Learning Center of an Iranian University Case Study
}

\author{
Peyman Akhavan and Majid Feyz Arefi \\ Department of Management and Soft Technologies, \\ Malek-Ashtar University of Technology, Tehran, Iran
}

\section{akhavan@iust.ac.ir; majidfeyzarefi@gmail.com}

\begin{abstract}
The purpose of this study is to obtain suitable quality criteria for evaluation of electronic content for virtual courses. We attempt to find the aspects which are important in developing e-content for virtual courses and to determine the criteria we need to judge for the quality and efficiency of learning objects and e-content. So we can classify the criteria and formulate conceptual framework for evaluation of e-content. Considering the literature, we identify suitable quality criteria and then apply Delphi for polling the experts' opinions. By developing the suggested conceptual framework, the contents of two courses which have been developed in an e-learning center of an Iranian University are evaluated by the related experts by using questionnaire and surveying. After reviewing the literature, frameworks and various models for evaluation of electronic content and polling the professors and experts' opinions in different fields including virtual learning, information technology, instructional technology and system engineering, 22 criteria were identified and they were classified in 4 groups as the following: quality of content and information, appropriateness of content with strategy, appropriateness of content with standard, appropriateness of content with instructional design. Network Security Essentials and Human Resource Management courses in an Iranian University were evaluated using the framework, and the findings indicated areas in design that were weak. The suggested framework in this study is shown to be a suitable tool for evaluating the virtual courses content in virtual universities and institutes. This framework can evaluate any virtual course content in 4 aspects: quality, strategy, standard and instructional design. This study helps virtual Learning service providers and electronic content developers in identifying the drawbacks and strengths in content development and in improving the content quality.
\end{abstract}

Material published as part of this publication, either on-line or in print, is copyrighted by the Informing Science Institute. Permission to make digital or paper copy of part or all of these works for personal or classroom use is granted without fee provided that the copies are not made or distributed for profit or commercial advantage AND that copies 1) bear this notice in full and 2) give the full citation on the first page. It is permissible to abstract these works so long as credit is given. To copy in all other cases or to republish or to post on a server or to redistribute to lists requires specific permission and payment of a fee. Contact Publisher@InformingScience.org to request redistribution permission.
Keywords : E-learning, Learning Objects, Electronic Content, Learning Object Evaluation, Virtual Learning Courses

\section{Introduction}

In recent years, education technologies have provided opportunity to benefit from efficient methods of learning (Geogieva, Todorov, \& Smrikarov, 2003). 
Also, diverse use of the Internet, web services and multimedia technologies have changed traditional learning into e-learning and have made it an important educational tool in universities (Chen, 2009; Shih, 2008). E-learning as a functional term has been introduced in the education field along with information technology, and in many countries, educational institutions, particularly universities, e-learning is a part of their long-term plans and they have put substantial investment into developing e-learning (Triantafillou, Pomportis, \& Georgiadou, 2002). Indeed all universities and educational institutes around the world have been designed around providing elearning in order to respond to increasing educational demands.

In many developed countries applications of e-learning courses is many times higher than the total higher education growth (Kurilovas \& Dagiene, 2009). Due to growing popularity of this type of training, to enhance the quality of learning in e-learning, it should be noted that the quality of the electronic content is an important part of the training.

New research conducted around the world shows that e-learning, virtual learning contexts and managed services provide benefits to institutions and training centers, but besides all these positive points, challenges remain such as: learning rate, effectiveness of educational content, quality of content, use of e-learning standards and instructional design. It is important that materials of the highest quality are produced, in this era of rapidly increasing use of e-learning, in order to achieve effective learning. (Rubin, Fernandes, Avgerinou, \& Moore, 2010; Kay \& Knaack, 2009; Gutierrez y Restrepo, Benavidez, \& Gutierrez, 2012; Raghuveer \& Tripathy, 2012).

This study identifies criteria for judging the quality and effectiveness of learning objects and econtent, as well as presenting a framework for evaluation of e-content for virtual courses and tests the framework on two courses.

This paper is organized as follows: first learning objects are explained in the context of instructional design, then existing frameworks for e-learning evaluation are discussed, next the methods used for this study are outlined, followed by a description of the iterative approach taken to develop the proposed framework. After testing the framework on two courses, the results are discussed.

\section{Learning Objects and Instructional Design}

In order to achieve high quality content, one of the most important issues is: attention to basic elements of content and enrichment of these components. Learning Objects (LO) are the basic elements of E-learning. As they correspond to the same standards, one can use any combination of them provided they match each other. By matching LOs, one can form bigger units of learning content such as: topics, lessons or whole courses (Fallon \& Brown, 2003).

Harman and Koohang asserted that "a learning object is not merely a chunk of information packaged to be used in instructional settings. A learning object, therefore, can include anything that has pedagogical value - digital or non-digital such as a case study, a film, a simulation, an audio, a video, an animation, a graphic image, a map, a book, or a discussion board so long as the object can be contextualized by individual learners. The learner must be able to make meaningful connections between the learning object and his/her experiences or knowledge he/she previously mastered" (p. 2). For the purpose of e-learning, a learning object is digital in nature (Koohang, Floyd, \& Stewart, 2011)

Daniel Churchill in his work has reviewed, various definitions and classifications for learning objects that, most investigators and institutes and universities around the world have offered and then he concludes "It seems that all learning objects are in common in terms of these features: 1. They are digital and they use diverse media (and often interactivity) to illustrate the data, information, reality, concepts and ideas. 2. The Learning objects are designed to reuse educational ca- 
pabilities" (p. 6). On this basis, he gives a general definition for learning objects as: "a learning object as a designed illustration for providing diverse educational facilities". Learning objects are web-based interactional tools which support important concepts using enhancement and encouragement or by guiding cognitive process in learners (Schiffman, 1986).

Barriers and empowerment in reusing learning objects are two important investigational fields in instructional technology. It is suggested in many publications that reusing learning objects not only saves time and expense, but also leads to a higher quality digital learning experience and thus economical and efficient learning (e.g., Kay \& Knaack, 2009).

It seems essential that electronic content must be evaluated due to its importance for the students as learners in e-learning courses because in e-learning face to face communication is reduced and e-content is playing a more important role in education.

\section{Systematic Approach to Developing Teaching Material}

Because of the critical importance of instructional design in enhancing the effectiveness of the learning content, a systematic and comprehensive approach to education and instructional design has been used.

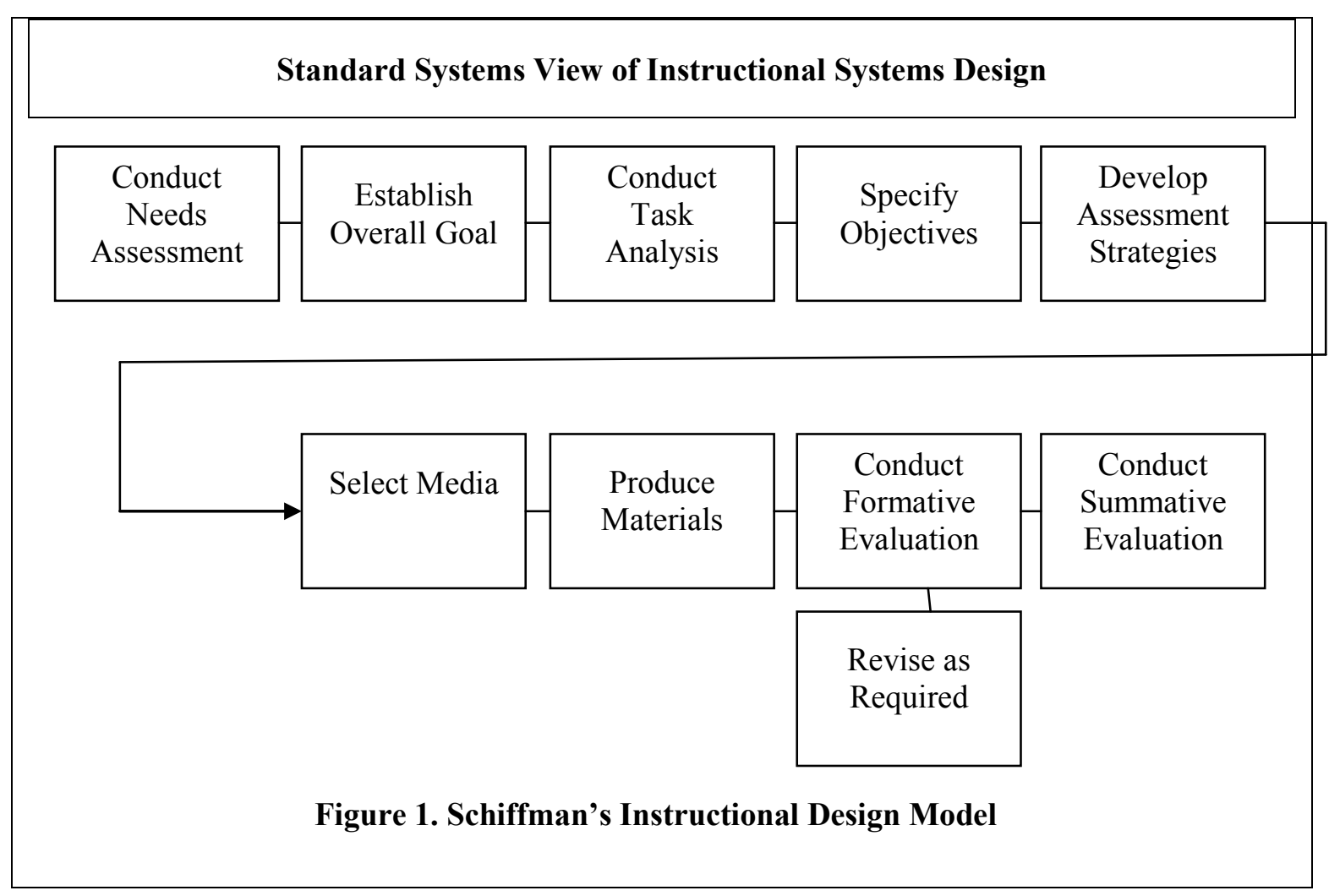

A systematic approach is of critical importance in enhancing the effectiveness of teaching materi$\mathrm{al}$, and was developed by focusing on language labs, teaching machines, programmed teaching, multimedia presentation and by using computers in education during the 1950s and 1960s. Systematic approaches are often similar to flowcharts in computer science with steps that designer undertakes to follow during the education process. A systematic approach, originating in military and business fields, encompasses defined goals, resource analysis, to practice a design and continuous assessment and improvement of a plan (Cohen \& Nycz, 2006). Schiffman (1986) in pre- 
sented a model (Figure 1) as an approach to standardising systems for producing educational systems.

With this approach and this model, criteria for evaluating content in terms of instructional design can be identified, e.g., Conduct Needs Assessment, Conduct Task Analysis, Develop Assessment Strategies.

\section{Learning Objects and E-content Evaluation Frameworks}

An LO is the smallest part of the content which itself could be a learning unit or meaning. The size of LO can be varied, but the best performance of LO is having a special learning aim. LO must be meaningful and independent of content, i.e. it must not depend on other parts of learning content to get completed. This means that each LO could be used in several lessons or courses (Fallon \& Brown, 2003).

A systematic and comprehensive approach to instructional design ensures that learning outcomes are achieved when e-learning material is used, so evaluation of learning objects, is needed to help maintain standards of learning material and learning objects, and a range of criteria have been developed for judging them (Kurilovas \& Dagiene, 2009). In providing rich content, many aspects of the content need to be evaluated, also the constituents of the content, i.e. "learning objects", should be evaluated. Vargo, Nesbit, and Archambault (2003) have developed a Learning Object Review Instrument (LORI) for evaluating learning objects. Version 1.3 of LORI uses 10 criteria to evaluate learning objects. Each measure was weighted equally and was rated on a fourpoint scale from "weak" to "moderate" to "strong" to "perfect" (Vargo et al., 2003). The LORI evolved over several versions, and Table 1 summarises the main criteria included in each version.

Table 1. Versions of LORI

\begin{tabular}{|c|c|c|}
\hline $\begin{array}{c}\text { Versions of } \\
\text { LORI } \\
\end{array}$ & Criteria & Reference \\
\hline LORI 1.3 & $\begin{array}{l}\text { 1-Presentation: aesthetics } \\
\text { 2-Presentation: Design for Learning } \\
\text { 3- Accuracy of content } \\
\text { 4-support for learning goals } \\
\text { 5-Motivation } \\
\text { 6-Interaction: usability } \\
\text { 7-Interaction: feedback and adaptation } \\
\text { 8-Reusability } \\
\text { 9-Metadata and interoperability compli- } \\
\text { ance } \\
\text { 10-Accessibility }\end{array}$ & $\begin{array}{c}\text { (Vargo, Nesbit, \& Archambault, } \\
\text { 2003) }\end{array}$ \\
\hline LORI 1.4 & $\begin{array}{l}\text { 1-Content Quality } \\
\text { 2-Learning Goal Alignment } \\
\text { 3-Feedback and adaptation } \\
\text { 4-Motivation } \\
\text { 5-Presentation design } \\
\text { 6-Interaction usability } \\
\text { 7-Reusability } \\
\text { 8-Value of accompanying instructor } \\
\text { guide }\end{array}$ & (Belfer, Nesbit, \& Leacock, 2002) \\
\hline
\end{tabular}




\begin{tabular}{|l|l|l|}
\hline & 1-Content quality & \\
2-Learning goal alignment & \\
3-Feedback and adaptation & 4-Motivation & (Leacock \& Nesbit, 2007) \\
& 5-Presentation design & \\
& 6-Interaction usability & \\
& 7-Accessibility & \\
& 8-Reusability & \\
& 9-Standards compliance & \\
\hline
\end{tabular}

As each model and framework is designed with regard to the particular circumstances and perspectives and case studies in a special environment, different versions of LORI also have their specific applications. Each researcher according to the scope of his work, and his expert opinion, uses different criteria from these versions.

The purpose of this study was to identify the challenges and issues that instructional designers face when designing and evaluating the effectiveness of a learning object. The focus of the study was on the methodology for deciding on the scope and sequence of a learning object and on selecting the appropriate instructional strategies to achieve the desired outcomes. The Learning Object Review Instrument (LORI), version 1.4 developed by Belfer, Nesbit, and Leacock (2002) was used to collect faculty's individual assessments of the quality of pharmacology learning objects and to determine areas for improvement.

In this paper, leading to the design of the proposed framework, we paid attention to all versions of LORI, and we reviewed all of the criteria included in these models. The last version of LORI (LORI 1.5) was informed by literature reviews and feedback from users in learning object quality studies and in professional development workshops for teachers and other stakeholders.

Krauss and Ally reported in 2005, a study based on LORI, the aim of which was to identify challenges and problems of instructional designers in design and evaluating the effectiveness of a learning object. Krauss and Ally presented a framework of eight criteria for evaluating learning objects and these criteria include: content quality, learning goal alignment, feedback, and adaptation, motivation, presentation design, Interaction usability, Reusability, student/Instructor Guides (Krauss \& Ally, 2005). Nash (2005) examined the current methods of using learning objects, and best practices to be considered, then by combining theories of learning, a new method was proposed to improve upon it. Factors that are presented in this paper, evaluating the quality of learning objects and their application, are important because, content quality depends on the quality of its constituent parts. In this paper, the factors for determining the usability of learning objects were presented as follows: relevance, usability, cultural appropriateness, infrastructure support, redundancy of access, size of object, relation to the infrastructure / delivery (Nash, 2005).

In this paper we have considered various dimensions for content, and by systematic approach, we pay attention to all aspects influencing the content. Therefore, we use these criteria in various dimensions for the proposed framework.

Buzzetto-Moore and Pinhey (2006) introduced 18 Qualitative criteria for evaluating learning objects of online courses at University of Maryland Eastern Shore. The most important criteria were: Technology requirements, objectives and outcomes, activities support learning, assessment, variety of tools to enhance interaction, course materials, student support, frequent and timely feedback, expectations for student discussion / chat participation, course content, navigation, display, multimedia (if appropriate), reusability (Buzzetto-More \& Pinhey, 2006). Six action areas for establishing Learning Object technical quality criteria were suggested by Paulsson and Naeve in 2006, these criteria include: 1) A narrow definition 2) A mapping taxonomy 3) More extensive 
standards 4) Best practice for use of existing standards 5) Architecture models 6) The separation of pedagogy from the supporting technology of LOs. The focus in this Model is on technical quality criteria for Learning Objects. Other quality criteria, such as pedagogical quality, usability or functional quality are within this scope. Other aspects of quality are addressed by Van Assche and Vuorikari (2006), who suggest a quality framework for the whole life cycle of learning objects (Paulsson \& Naeve, 2006). The MELT content audit in 2007, included an in depth examination of project partners' existing content quality guidelines, and they proposed a checklist to help them make decisions about what content from their repositories for enrichment in the project should be made available. This checklist is divided into five categories: pedagogical, usability, reusability, accessibility and production. This list is by no means new and not all of the criteria can always be applied to Learning Objects. The MELT project partners seek to provide access to learning content that meets nationally (European) recognized quality criteria (MELT, 2007).

SREB (Southern Regional Education Board) in 2007 provided a checklist for learning object evaluation, with the aim of improving the quality of its training programs. This checklist has 10 criteria that include the following: 1) Content quality 2) Learning goal alignment 3) feedback 4) Motivation 5) Presentation design 6) Interface Usability 7) Accessibility 8) Reusability 9) Standards compliance 10) Intellectual property and copyright (SREB-SCORE, 2007). Tele-University of Quebec in 2007 sought to improve the effectiveness, efficiency and flexibility of learning objects, by implementing a quality assurance strategy called "quality for reuse" (Q4R), for the scientific projects that were started at the university, as well as proper storing and retrieval strategies. They have organized these strategies into four main groups, which include: organizational strategies, and then three strategies inspired by the life-cycle of a LO, that is from its conception to its use/reuse (adaptations) (Q4R, 2007). In June 2008 the Ministry of Education and Science of Lithuania listed criteria for technical evaluation of learning objects to help teach computing, and set out to take the assessment tool called the 'Lithuanian learning objects evaluation tool'. The most important criteria are: User interface, LOs arrangement possibilities, communication and collaboration possibilities and tools and technical features (Kubilinskiene \& Kurilovas, 2008).

Kurilovas and Dagiene in 2009 combined the frameworks of Vargo et al. (2003), Paulsson \& Naeve (2006), MELT (2007), Q4R (2007) and studies in 2007 by Kurilovas, to propose an original set of LO evaluation criteria, called "Recommended learning objects technical evaluation tool". This tool includes LO technical evaluation criteria suitable for different LO life-cycle stages. These criteria are:

* The first criteria (before LO inclusion in the LOR):

$\checkmark$ Narrow definition compliance

$\checkmark$ Reusability level: (1-interoperability, 2-decontextualisation level, 3-cultural / learning diversity principles, 4-accessibility)

$\checkmark$ LO architecture

$\checkmark$ Working stability

$\checkmark$ Design and usability

* The second criteria (during LO inclusion in the LOR):

$\checkmark$ Membership or contribution control strategies

$\checkmark$ Technical interoperability

* The third criteria (after LO inclusion in the LOR):

$\checkmark$ Retrieval quality

$\checkmark$ Information quality

The following table (Table 2) summarises findings from the literature and shows the criteria found by researchers and specialized work groups. 
Table 2. The preliminary criteria of framework

\begin{tabular}{|c|c|}
\hline Criteria & References \\
\hline 1.Course Content & Buzzetto and Pinhey(2006) \\
\hline 2.Accuracy of Content & $\begin{array}{c}\text { Belfer et al(2002), Nesbit et al(2004), Krauss and Ally(2005), } \\
\text { Buzzetto and Pinhey(2006), SREB(2007) }\end{array}$ \\
\hline 3.Accessibility & $\begin{array}{l}\text { Vargo et al(2002), Nesbit et al(2004), SREB(2007), } \\
\text { MELT(2007), Kurilovas and Dagiene(2009) }\end{array}$ \\
\hline 4.Pedagogical Decontextualisation Level & Kurilovas and Dagiene(2009) \\
\hline 5.Organizational Strategies & Q4R Project(2007) \\
\hline 6.Infrastructure Support Strategies & Susan Nash(2005), Buzzetto and Pinhey(2006) \\
\hline 7.Support Activities for Learning Goals & Vargo et al(2002), Buzzetto and Pinhey(2006) \\
\hline 8.A Variety of Tools Enhance Interaction & 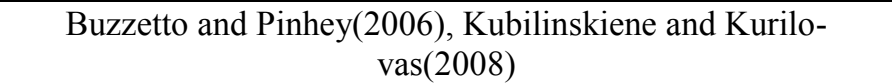 \\
\hline 9.Interaction Usability & $\begin{array}{c}\text { Vargo et al(2002), Belfer et al(2002), Nesbit et al(2004), } \\
\text { Krauss and Ally(2005), Susan Nash(2005), MELT(2007), Ku- } \\
\text { rilovas and Dagiene(2009) }\end{array}$ \\
\hline 10.Reusability & $\begin{array}{l}\text { Vargo et al(2002), Belfer et al(2002), Nesbit et al(2004), } \\
\text { Krauss and Ally(2005), Buzzetto and Pinhey(2006), } \\
\text { MELT(2007), SREB(2007), Kurilovas and Dagiene(2009) }\end{array}$ \\
\hline 11.More Extensive Standards & Paulsson and Naeve(2006) \\
\hline 12.Size of Object & Susan Nash(2005) \\
\hline 13.Retrieval Quality & Kurilovas and Dagiene(2009) \\
\hline 14.Technical Features & Kubilinskiene and Kurilovas(2008) \\
\hline 15.Presentation Design (Display) & $\begin{array}{c}\text { Vargo et al(2002), Belfer et al(2002), Nesbit et al(2004), } \\
\text { Krauss and Ally(2005), SREB(2007), Buzzetto and Pin- } \\
\text { hey(2006) }\end{array}$ \\
\hline 16.Learning Goal Alignment & $\begin{array}{c}\text { Belfer et al(2002), Nesbit et al(2004), Krauss and Ally(2005), } \\
\text { Buzzetto and Pinhey(2006), SREB(2007) }\end{array}$ \\
\hline 17.LO Architecture & Kurilovas and Dagiene(2009) \\
\hline 18. Navigation & Buzzetto and Pinhey(2006), Kurilovas and Dagiene(2009) \\
\hline $\begin{array}{l}\text { 19. Cultural Appropriateness and } \\
\text { Diversity }\end{array}$ & Susan Nash(2005), Kurilovas and Dagiene(2009) \\
\hline
\end{tabular}

Each of the frameworks in Table 2 and models and e-content has its limitations because of the unique activity of the respective institutions, model or the strategy and purpose of the researchers. According to the above table, LORI, Krauss \& Ally and SREB have many identical scales and their focus is on e-content evaluation and qualitative promotion of content with respect to certain standards components. There is limited focus on metadata, object details and organization' technical features and strategies, but Q4R has 4 main strategies to guarantee the quality of LO which Kurilovas and Dagiene (2009) offered within a more complex model by using them as the base 
and addressing some of the limitations including: LORI 1.3, LORI 1.5, MELT (2007), SREB (2007). They did not investigate the different steps in the life cycle of LOs. Nor did Q4R investigate the technical evaluation scales of LOs prior to their location in LO's store. Neither did LORI 1.3, LORI 1.5, MELT, SREB or Q4R sufficiently investigate scales of reusability. The Kurilovas and Dagiene (2009) model is focused on technical evaluation of LOs, largely ignoring strategies and learning purposes and as a result also ignoring appropriateness of the content and strategy.

The proposed framework is presented in Section 5, and in the following section, the four dimensions of the framework are explained. It can be seen that criteria for the quality of content, learning strategies and organizational strategies, e-learning standards and instructional design are included in the four dimensions. This study attempts to determine a framework for evaluating electronic content and learning objects taking into consideration all of the aspects identified by various researchers, and concentrating on existing limitations, gaps and challenges for the frameworks under question.

The main part of this study includes questions about the quality of electronic content. The following questions being asked: Are there suitable frameworks for evaluating the quality of electronic content? Do current standards for e-learning and learning objects have suitable quality parameters? What are the parameters, frameworks and associated quality criteria needed for evaluating electronic content?

\section{Methods of Study}

We used the Delphi Method to determine the validity of the proposed framework, because of the need to review the criteria by experts in various fields, and also because of the exploratory nature of this research, i.e. the dimensions and criteria required to cover all aspects of evaluation.

Delphi was designed as a structured communication technique by RAND in the 1950s to collect data through collective opinion polling (Gallenseon, Heins, \& Heins, 2002).

In this study experts' opinions were used to assess the validity of the proposed framework. In this two-round Delphi method, the panel of experts included 16 professors and experts in e-learning, information technology, computer engineering, instructional technology and systems engineering fields. The questionnaire used was based on a Likert Scale: 1.Strongly unimportant, 2. Unimportant, 3. Neutral, 4. Important, and 5. Strongly important. The research structure is illustrated in figure 2 .

Several specialized sessions were held, firstly to ask about the proposed dimensions, using the questionnaire given in Appendix B, then asking about the criteria, using the questionnaire given in Appendix C.

Apart from the questionnaire, a survey was conducted with interviews and meetings with experts. Interviews were used to elicit views from various experts on the different dimensions of the framework.

These interviews were conducted to finalize and complete identification of the criteria, and put the criteria into dimensions. Questions such as the following were included in the interviews:

Are the criteria already identified from the literature review and Delphi method (survey) appropriate?

Are the criteria placed in each dimension adequate for evaluating the content of the following? 


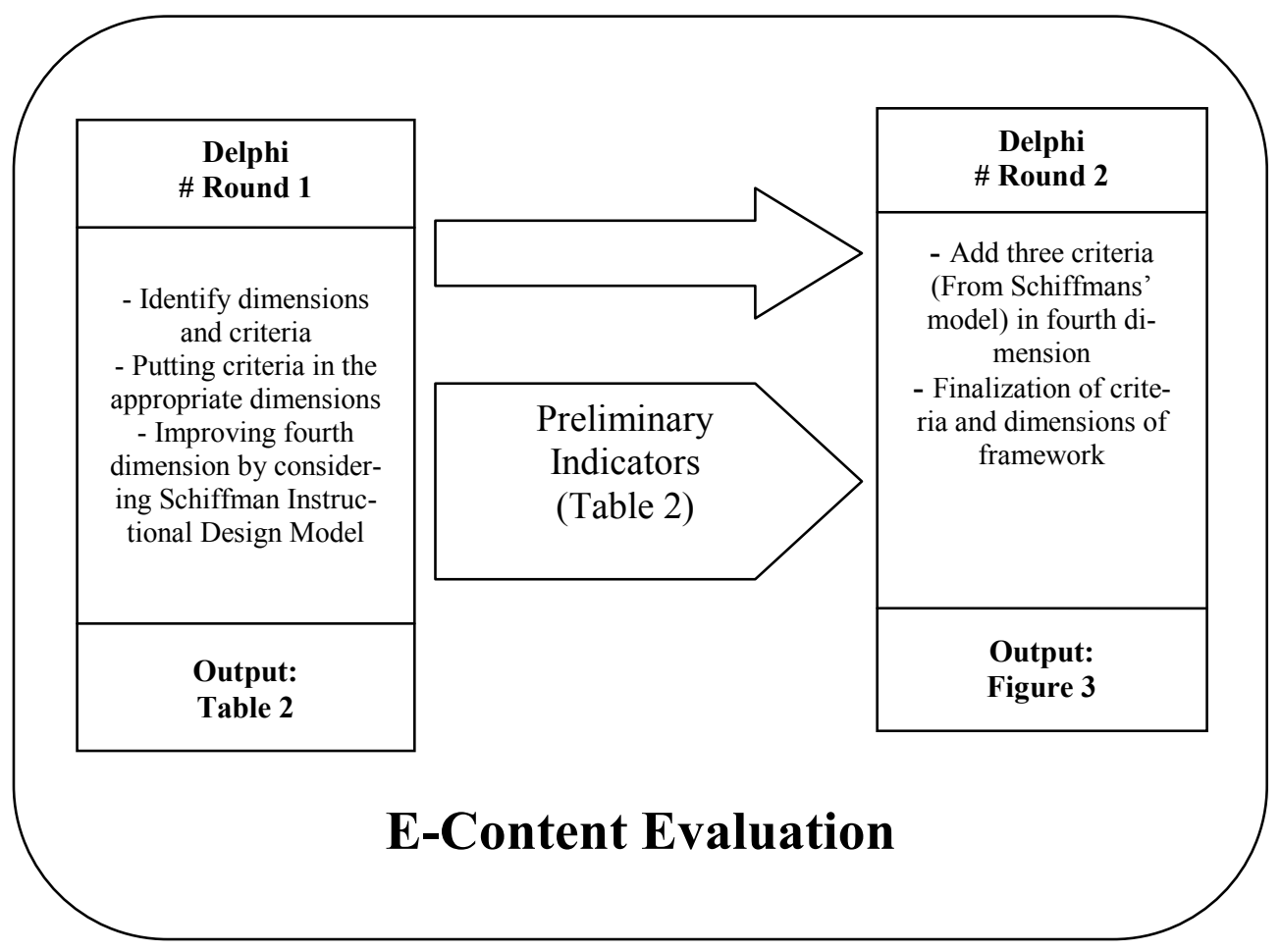

Figure 2. Research Structure

After reviewing the literature on learning objects and e-content evaluation, and also after examining the previous credible quality criteria, the researchers held meetings with the supervisor of an e-learning center of a university. In these meetings, initial criteria were identified, and meetings were held with other e-learning experts, in the form of expert panels and specialized working groups. As a result of these meetings, the criteria for e-content were classified in four dimensions: 1. Quality of content and information, 2. Appropriateness of content with strategy, 3. Appropriateness of content with standard, 4. Appropriateness of content with instructional design.

After identification of e-content dimensions, in the first part of Delphi Method, the experts were given a five-scale-Likert questionnaire regarding the dimensions and their significance as well as asking for other possible dimensions from their view-point. After this, the framework dimensions validity was assessed and they were prioritized based on average expert opinion from a five point Likert scale. Then, the fourth dimension of the framework "Appropriateness of content with instructional design" was added to match Shirl S. Schiffman's suggested Model (1986) for a systematic approach to education and a valid model of educational design. Using an instructional technology expert's opinion, the following three criteria were added to instructional design: conduct needs assessment, develop assessment strategies (specify evaluation strategies) and conduct task analysis (teacher and student).

In the second part of the Delphi Method, a questionnaire with 22 criteria was given using a Likert scale so that the experts could indicate their views about the criteria or other criteria that they felt suitable to be mentioned, and finally, after two rounds of the Delphi method, the indicators of the framework were fully identified and validated by experts, shown in Figure 3.

\section{Validity and Reliability of Questionnaire}

For validity purposes we consulted with the experts in order to edit the questions. Then the reliability rate for the results was measured using SPSS 19 software as a Cronbach Alpha (0.89) value. 
Table 3. Reliability testing using Cronbach's alpha

\begin{tabular}{|c|c|}
\hline Cronbach Alpha & N \\
\hline 0.890 & 22 \\
\hline
\end{tabular}

To confirm the validity of the study, Cronbach's alpha coefficient should be greater than 0.75 . In this study, Cronbach's alpha coefficient was 0.890 (Table 3), which indicates the validity of the research.

After polling from experts about dimensions and parameters and collecting data, the normality of data was tested using one-dimensional Kolmogorov- Smirnov Test (K-S Test). This test compares empirical cumulative distribution function one-dimensionally with conceptual (expected) cumulative distribution function in a sequential variant. Appendix A shows average rates and standard deviation for each dimension of the framework and presents average rates and standard deviation for each indicator of the framework. The results (appendix A), show that the mean of all dimensions is higher than 4.06 and the mean of all indicators is higher than 3.75 and the standard deviation for all dimensions is lower than 0.680 and the standard deviation for all indicators is lower than 0.834 . Hence the views of the experts suggest all dimensions and indicators are rated as very important.

\section{Design of the Proposed E-Content Evaluation Framework Based on the Delphi experts' feedback}

First, the literature review was carried out by the authors, and the initial criteria was given to the experts, then by meeting them face to face, in two-rounds of Delphi, appropriate criteria were identified and were separated in to four dimensions. (All experts from the first round were also present in the second round and several experts were added in the second round, to give perspectives from experts who had not seen the original list of criteria.)

The first round Delphi:

$\checkmark$ Identify Dimensions and criteria

$\checkmark$ Putting criteria in the appropriate dimensions

$\checkmark$ Improving fourth dimension by considering Schiffman Instructional Design Model

The second round of Delphi:

$\checkmark$ Add three criteria (From Schiffmans' model) in fourth dimension

$\checkmark$ Finalization of criteria and dimensions of framework

In Figure 3 the resulting conceptual framework of evaluated e-content is shown. There follows a brief explanation of each criteria. 


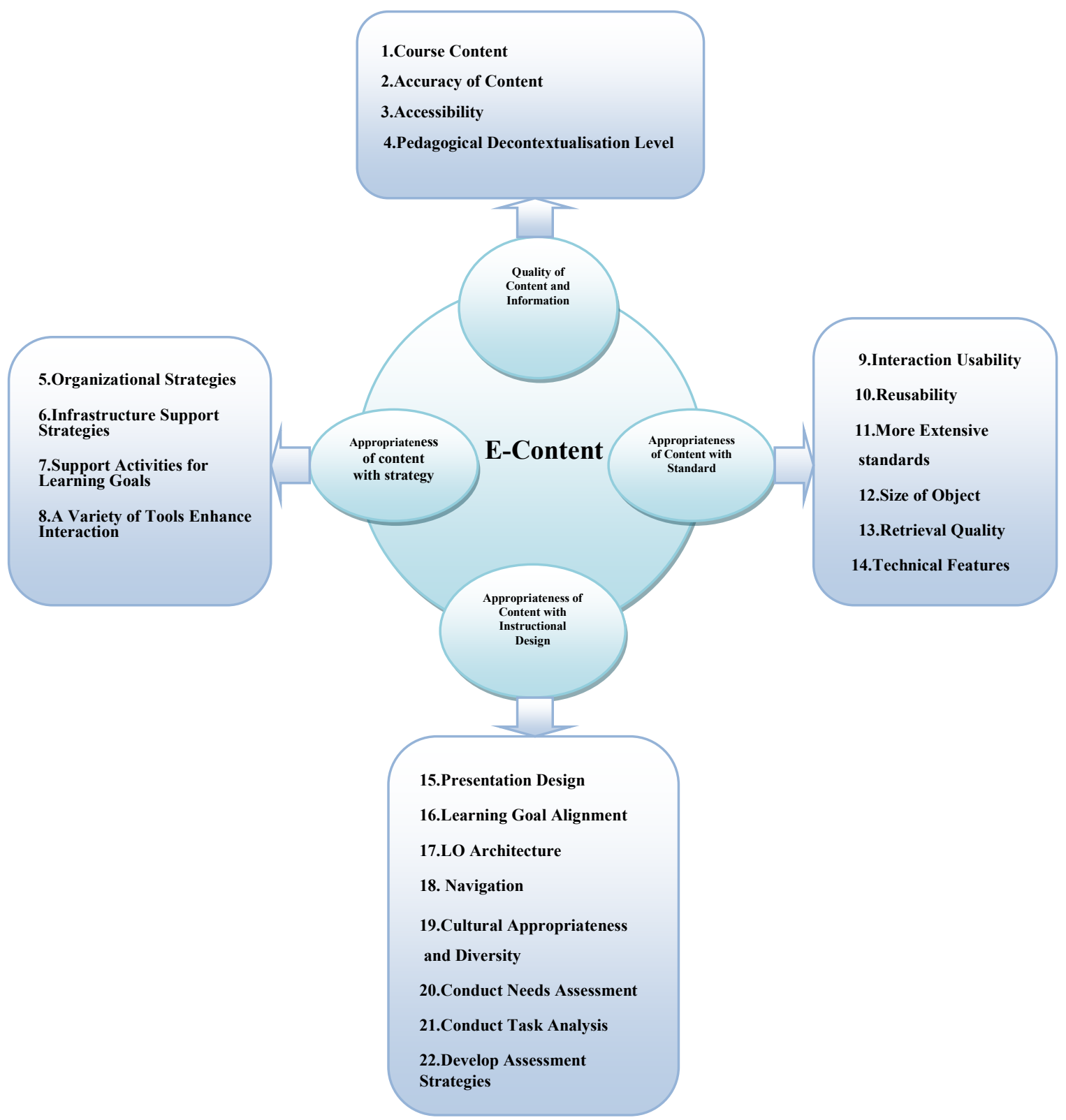

Figure 3. The conceptual framework of e-content evaluation

\section{Quality of Content and Information}

$>$ Course content: Defined as transparency, significance and enrichment of the content.

$>$ Accuracy of Content: meaning Correctness, accuracy and having suitable level of details and balanced ideas.

$>$ Accessibility: Design of controls and presentation formats to accommodate disabled and mobile learners. 
$>$ Pedagogical Decontextualisation Level: Content and learning objects must be accessible and divisible into subparts. In other words, educational subparts can be used in different context and courses.

\section{Appropriateness of Content with Strategy}

$>$ Organizational Strategies: The created content must be compliant with the strategies of the organization, and the creator of the content must be aware of the strategies of the organization such as copyright policy and management support of different policies of content creation.

$>$ Infrastructure Support Strategies: The creator of the content must know the proposed infrastructure technologies and they must be used appropriately. The strategies include wideband system, multiple servers and high capacity for storing large files.

$>$ Support Activities for Learning Goals: Strategies must be developed for supporting all activities related to goals and results of learning.

$>$ A Variety of Tools Enhance Interaction: The creator of the content must consider the strategies of the organization for using various communicational tools to facilitate sustainable relations with learners in the content creation process.

\section{Appropriateness of Content with Standard}

$>$ Interaction Usability: Learning objects and electronic content must be created such that they facilitate interrelation and user access of appropriate quality.

$>$ Reusability: The learning objects within the electronic content can be exchanged among different courses with no changes made to them, they can be used, edited and improved easily with reasonable longevity and they can have many audiences among learners in virtual learning courses.

$>$ More Extensive Standards: Using various e-learning standards for developing learning objects and electronic content.

$>$ Size of Object: The content creator must consider the size and volume of learning objects, and its potential and limits for the students.

$>$ Retrieval Quality: The quality of learning objects restoration using different methods with various qualities from the content creator point of view.

$>$ Technical Features: appropriate standards must be used for creating systematic content.

\section{Appropriateness of Content with Instructional Design:}

$>$ Presentation Design (Display): The content must be designed considering visibility, audiology, attraction, transparency, coherence, image display, colors and graphical elements related to the course learning goals.

$>$ Learning Goal Alignment: The design of e-content must be compatible to learning goals in relation to learner's activities with sufficient attention paid to learner's specificity and perception.

> LO Architecture: The layers and levels of information, concepts and applied logics must be distinguished while designing learning objects and electronic content.

$>$ Navigation: Clarity and transparency of sequences of existing topics and concepts of content and accuracy of all links in the content in order that students can understand the interrelation between the topics.

$>$ Cultural Appropriateness and Diversity: The content must be created in international level (multilingual, multicultural) in order to communicate well with the learner. 
$>$ Conduct Needs Assessment: The learner's educational needs must be adequately evaluated by the content creator.

$>$ Conduct Task Analysis: The content designer must determine the approaches to learner evaluation for the content, in order that the learner knows the important priorities in the different subjects and how he or she must prepare himself or herself for examination and evaluation.

$>$ Develop Assessment Strategies: The professor's task and the learner's task must be determined.

The Research framework and its components were described in this section. In the next section, the authors will show how the framework was applied to evaluate two test courses.

\section{Application of the Evaluation Framework}

The E-learning center of an Iranian University delivers M.Sc. courses in Network Security and Information and an MBA programme. After consulting with the E-learning center supervisor, "Network Security Essentials" an important course in M.Sc. course of Network Security and Information and also "Human Resource Management" from the MBA course were selected as sample courses to be evaluated. The researchers were interested in finding out whether the proposed framework was applicable for evaluating existing courses, and whether the evaluation would indicate parts of the courses that required improved design.

The content of the selected courses (Network Security Essentials and Human Resource Management) was evaluated by 3 experts using the suggested model, with a questionnaire containing 22 criteria (in Appendix C) based on a Likert Scale. (1.Completely disagree 2. Disagree 3. No opinion 4. Agree 5. Completely agree). The following tables show the results (Tables 4 and 5).

The results of evaluation of the Network Security Essentials and Human Resource Management courses show that in both cases appropriateness of content with standard appears to have been given less priority than other dimensions by the course developer.

According to the evaluation that was performed in this paper, it can be seen that the proposed framework consisting of four dimensions showed the strengths and weaknesses of electronic content from different aspects, and significant areas of improvement can be identified. As the evaluation conducted in this study found the electronic content of these courses, in terms of e-learning standards and instructional design and technology components, was of lower standard. The areas that were identified, by criteria of the framework, are more clearly identifiable using this framework.

Table 4. Results of Evaluation of e-content (Network Security Essentials)

\begin{tabular}{|c|c|c|c|c|c|c|}
\hline \multicolumn{7}{|c|}{ Network Security Essentials } \\
\hline $\begin{array}{c}\text { Score } \\
\text { of 20 }\end{array}$ & $\begin{array}{c}\text { Mean of } \\
\text { dimensions }\end{array}$ & $\begin{array}{c}\text { Appropriateness } \\
\text { of content with } \\
\text { instructional } \\
\text { design }\end{array}$ & $\begin{array}{c}\text { Appropriateness } \\
\text { of content with } \\
\text { standard }\end{array}$ & $\begin{array}{c}\text { Appropriateness } \\
\text { of content with } \\
\text { strategy }\end{array}$ & $\begin{array}{c}\text { Quality of } \\
\text { content and } \\
\text { information }\end{array}$ & $\begin{array}{c}\text { Dimensions } \\
\text { Experts }\end{array}$ \\
\hline 14.12 & 3.53 & 3.875 & 3 & 4 & 3.25 & $\begin{array}{c}\text { First } \\
\text { expert }\end{array}$ \\
\hline 15.16 & 3.79 & 3.5 & 3.16 & 4.5 & 4 & $\begin{array}{c}\text { Second } \\
\text { expert }\end{array}$ \\
\hline 13.70 & 3.42 & 3.375 & 3.33 & 3.5 & 3.5 & $\begin{array}{c}\text { Third } \\
\text { expert }\end{array}$ \\
\hline $\mathbf{1 4 . 3 3}$ & 3.58 & 3.58 & 3.16 & 4 & 3.58 & Mean \\
\hline
\end{tabular}


Table 5. Results of Evaluation of e-content (Human Resource Management)

\begin{tabular}{|c|c|c|c|c|c|c|}
\hline \multicolumn{7}{|c|}{ Human Resource Management } \\
\hline $\begin{array}{c}\text { Score } \\
\text { of } 20\end{array}$ & $\begin{array}{c}\text { Mean of } \\
\text { dimension } \\
s\end{array}$ & $\begin{array}{c}\text { Appropriatenes } \\
\text { s of content } \\
\text { with } \\
\text { instructional } \\
\text { design }\end{array}$ & $\begin{array}{l}\text { Appropriatenes } \\
\text { s of content } \\
\text { with standard }\end{array}$ & $\begin{array}{l}\text { Appropriatenes } \\
\text { s of content } \\
\text { with strategy }\end{array}$ & $\begin{array}{c}\text { Quality of } \\
\text { content } \\
\text { and } \\
\text { informatio } \\
\text { n }\end{array}$ & Dimension \\
\hline 15 & 3.75 & 3.75 & 3.5 & 3.75 & 4 & $\begin{array}{c}\text { First } \\
\text { expert }\end{array}$ \\
\hline $\begin{array}{c}14.7 \\
1\end{array}$ & 3.68 & 3.875 & 3.33 & 4 & 3.5 & $\begin{array}{l}\text { Second } \\
\text { expert }\end{array}$ \\
\hline $\begin{array}{c}14.8 \\
3\end{array}$ & 3.71 & 4 & 3.33 & 3.5 & 4 & $\begin{array}{l}\text { Third } \\
\text { expert }\end{array}$ \\
\hline $\begin{array}{c}14.8 \\
5\end{array}$ & 3.71 & 3.875 & 3.39 & 3.75 & 3.83 & Mean \\
\hline
\end{tabular}

\section{Discussion}

As mentioned in the Methodology section, experts examined the importance of the criteria, shown in Table 6.

Table 6. The importance of criteria

\begin{tabular}{|c|c|c|}
\hline Criteria & Priority & Mean (Likert) \\
\hline $\begin{array}{c}\text { Course Content, Pedagogical Decontextualisation Level, } \\
\text { Infrastructure Support Strategies, Conduct Needs Assess- } \\
\text { ment, Develop Assessment Strategies }\end{array}$ & +++ & $4.5 \leq$ Mean $<5$ \\
\hline $\begin{array}{c}\text { Accuracy of Content, Accessibility, Organizational Strate- } \\
\text { gies, Support Activities for Learning Goals, A Variety of } \\
\text { Tools Enhance Interaction, Interaction Usability, More } \\
\text { Extensive Standards, Technical Features, Presentation De- } \\
\text { sign (Display), Learning Goal Alignment, LO Architec- } \\
\text { ture, Navigation, Cultural Appropriateness and Diversity, } \\
\text { Conduct Task Analysis }\end{array}$ & ++ & $4 \leq$ Mean $<4.5$ \\
\hline Reusability, Size of Object, Retrieval Quality & & \\
\hline
\end{tabular}

The purpose of evaluating the virtual courses in the e-learning center of an Iranian University is to improve the quality of the course content through considering all effective dimensions in content enrichment. Therefore, the drawbacks and strengths of content are identified by this evaluation and they may be corrected and improved by developers. We evaluated two courses and found that the developers were weak in design of the component in terms of e-learning standards and instructional design. In regard to the indicators in the suggested framework, it can be said that the defined indicators in the following dimensions have been paid lower attention than other indicators and the content addressed less well by developers. In the first dimension, indicator of the pedagogical decontextualisation level; in the second dimension, indication that a variety of tools enhance interaction; in the third dimension, indicators of interaction usability, reusability, more extensive standards and retrieval quality; and in the fourth dimension, indicators of LO architecture, navigation and cultural appropriateness and diversity. In the case study of this research, significant gaps and weaknesses and areas of improvement in the content, were identified by using the proposed framework. Recommendations were offered to address weaknesses and improve the 
content. Then appropriate feedback was given to the content creators and e-learning providers of the university. Therefore, it is suggested that for improving quality of course content and to enrich design of learning objects, the curriculum developers should be more familiar with quality indicators and dimensions of e-content. Training courses could be provided for developers so that they become familiar with e-learning standards and models of instructional technology and design. The proposed framework in this study has potential to guide content developers in using the dimensions of e-content evaluation.

\section{Conclusion}

In this study, e-content evaluation and challenges in this field were considered important and from the literature it was proposed that a framework for evaluation of e-content of higher education curriculum could be developed as a tool for developers. Then, the most important models and frameworks for evaluation in this field were introduced. Thus, following from previous studies, models and frameworks given by investigators, practitioners and universities and e-learning institutes were considered, and indicators related to e-content were identified and classified in four dimensions. The validity of the four-dimension framework of e-content evaluation with 19 indicators was assessed, using the related experts and practitioners' opinions. Some experts and professors in instructional design suggested that instructional design dimension should be compared to one valid instructional design model and so three indicators were added to the suggested instructional design. Hence, a framework with 22 indicators and 4 dimensions was developed as follows: quality of content and information, appropriateness of content with strategy, appropriateness of content with standard, appropriateness of content with instructional design.

The resulting four-dimension framework in this study was shown, through testing on 2 courses, to be a suitable tool for evaluation of e-content in universities and institutes of electronic training and also for improving the quality of e-content. The framework will help raise the efficiency and effectiveness of e-learning content for students in virtual education courses. In addressing the research questions the following observations were made:

Are there suitable frameworks for evaluating the quality of electronic content?

The existing frameworks included a range of criteria for evaluating electronic content. Some frameworks evaluate electronic training with criteria for learning objects, electronic content and instructional design criteria. Others evaluate only learning objects and they believe that learning objects play a major role in developing curriculum content. But there is no framework with specific dimensions and specific measurable indicators for each dimension. In other words, there is no framework which can evaluate electronic content from the viewpoint of a number of suitable quality dimensions. This study attempts to present a suitable framework for evaluating electronic content with sufficient dimensions and quality criteria, based on existing literature and by consulting with different experts.

Do current standards for e-learning have suitable quality parameters?

Using standards may help the development of learning objects and electronic content, accessibility, reusability, exchangeability in different contexts and their durability. But even using the standards of different fields of electronic training, cannot guarantee high quality electronic content, and in fact, one cannot depend only on standards for creating electronic content because other indexes affect the quality of electronic content of a course. Developers can create electronic content solely based on standards, but the learners would not be able to easily relate to it and therefore, the content might be inefficient. 
$>$ What are the parameters that frameworks and the related quality criteria need for evaluating electronic content?

The proposed framework is applicable for virtual universities and institutions where virtual courses are presented. The evaluation of electronic content must be multidimensional and based on a range of criteria by consulting the experts as has been proposed in this study.

This study reveals benefits and implications for professors, distant learning centers and academics. The professors can understand existing challenges and gaps in content they have created, and by evaluating electronic content of courses and they can try to improve it. This improvement can impact on student satisfaction, higher efficiency of content and higher learning achievements for students. By conducting evaluation and indentifying the problems and by creating opportunity for improving the content, improvement in distant learning can be successfully accomplished. More efficient electronic training is possible through performing such evaluation studies as has been conducted.

\section{Suggestions for Future Study}

Since e-learning has become pervasive and most universities are tending to practice this trend towards e-learning, the quality of e-content and learners' instructional needs based on instructional design in educational technology disciplines need to be addressed. It is suggested that the following topics are pursued and conducted in future studies:

- Exploring the model and the method of requirement assessment compatible to ISO10015 with e-learning standards approach.

- Giving the model (framework) of electronic curriculum content creation based on cultural and social visions with e-learning standards approach.

- Applying this framework to evaluate electronic content in other disciplines

\section{References}

Belfer, K., Nesbit, J. \& Leacock, T. (2002). Learning Object Review Instrument (LORI). Version 1.4.

Buzzetto-More, N., and Pinhey, K. (2006). Guidelines and standards for the development of fully online learning objects. Interdisciplinary Journal of Knowledge and Learning Objects, 2, 95-104. Retrieved from http://www.ijello.org/Volume2/v2p095-104Buzzetto.pdf

Chen, M.P. (2009). An evaluation of the ELNP e-learning quality assurance program: Perspectives of gap analysis and innovation diffusion. Educational Technology \& Society, 12(1), 18-33.

Churchill, D. (2007). Toward a useful classification of learning objects. Educational Technology Research and Development, 55(5), 479-497.

Cohen, E. \& Nycz, M. (2006). Learning objects e-learning: An informing science perspective. Interdisciplinary Journal of Knowledge and Learning Objects, 2, 23-24. Retrieved from http://ijklo.org/Volume2/v2p023-034Cohen32.pdf

Fallon, C., \& Brown, S. (2003). E-Learning standards: A guide to purchasing, developing and deploying standards - conformant e-learning. CRC Press.

Gallenseon, A., Heins, J., \& Heins, T. (2002). Macromedia MX: Creating learning objects. [Macromedia White Paper]. Macromedia Inc. Retrieved 6/02/06 from http://download.macromedia.com/pub/elearning/objects/mx_creating_lo.pdf

Geogieva, G., Todorov, G., \& Smrikarov, A. (2003). A model of virtual university -Some problems during its development. Proceeding of the $4^{\text {th }}$ International Conference on Computer Systems and Technologies: E-learning. Bulgaria. ACM Press. 
Gutierrez y Restrepo, E., Benavidez, C., \& Gutierrez, H. (2012). The challenge of teaching to create accessible learning objects to higher education lecturers. Procedia Computer Science, 14, 371-381.

Harman, K., \& Koohang, A. (2005). Discussion board: A learning object. Interdisciplinary Journal of Knowledge \& Learning Objects, 1, 67-77. Retrieved from http://www.ijello.org/Volume1/v1p067077Harman.pdf

Kay, R. H., \& Knaack, L. (2009). Assessing learning, quality and engagement in learning objects: The Learning Object Evaluation Scale for Students (LOES-S). Educational Technology Research and Development, 57, 147-168.

Koohang, A., Floyd, K., \& Stewart, C. (2011). Design of an open source learning objects authoring tool-the LO creator. Interdisciplinary Journal of Knowledge \& Learning Objects, 7, 111-123. Retrieved from http://www.ijello.org/Volume7/IJELLOv7p111-123Koohang746.pdf

Krauss, F., \& Ally, M. (2005). A study of the design and evaluation of a learning object and implications for content development. Interdisciplinary Journal of Knowledge and Learning Objects, 1, 1-22. Retrieved from http://www.ijello.org/Volume1/v1p001-022Krauss.pdf

Kubilinskienė, S., \& Kurilovas, E. (2008). Lithuanian Learning Objects Technical Evaluation Tool and its application in learning object metadata repository. In Informatics Education Contributing Across the Curriculum: Proceedings of the 3rd International Conference "Informatics in Secondary Schools Evolution and Perspective" (ISSEP-2008). Torun, Poland, July 1-4, 2008. Selected papers, 147 158.

Kurilovas, E., \& Dagiene, V. (2009). Learning objects and virtual learning environments technical evaluation criteria. Electronic Journal of E-Learning, 7(2), 127-136.

Leacock, T. L., \& Nesbit, J. C. (2007). A framework for evaluating the quality of multimedia learning resources. Educational Technology \& Society, 10(2), 44-59.

MELT. (2007). Metadata Ecology for Learning and Teaching project web site. [online]. http://meltproject.eun.org

Nash, S. S. (2005). Learning objects, learning object repositories, and learning theory: Preliminary best practices for online courses. Interdisciplinary Journal of Knowledge and Learning Objects, 1, 217-228. Retrieved from http://www.ijello.org/Volume1/v1p217-228Nash.pdf

Paulsson, F., \& Naeve, A. (2006). Establishing technical quality criteria for learning objects. Retrieved from http://www.frepa.org/wp/wp-content/files/paulsson-Establ-Tech-Qual_finalv1.pdf

Q4R. (2007). Quality for Reuse project web site. http://www.q4r.org

Raghuveer, V. R., \& Tripathy, B. K. (2012). An object oriented approach to improve the precision of learning object retrieval in a self learning environment. Interdisciplinary Journal of E-Learning and Learning Objects, 8, 193-214. Retrieved from http://www.ijello.org/Volume8/IJELLOv8p193214Raghuveer0818.pdf

Rubin, B., Fernandes, R., Avgerinou, M. D., \& Moore, J. (2010). The effect of learning management systems on student and faculty outcomes. The Internet and Higher Education, 13(1-2), 82-83.

Schiffman, S. S. (1986). Instructional systems design: Five views of the field. Journal of Instructional Development, 9(3), 14-21.

Shih, H. (2008). Using a cognitive-motivation-control view to access the adoption intention for Web based learning. Computer \& Education, 50, 327-337.

SREB-SCORE. (2007). Checklist for evaluating SREB-SCORE Learning objects, educational Technology Cooperative.

Triantafillou, E., Pomportis, A., \& Georgiadou, E. (2002). AES-CS: Adaptive Educational System Based on Cognitive Styles. Proceedings of OFAH 2002 workshop Systems for Web-based Education.

Van Assche, F. \& Vuorikari, R. (2006). A framework for quality of learning resources. In U-D Ehlers \& J. M. Pawlowski (Eds.), Handbook on quality and standardisation in e-learning (pp. 443-456). Berlin: Springer. 
Vargo, J., Nesbit, J. C., \& Archambault, A. (2003). Learning object evaluation: Computer-mediated collaboration and inter-rater reliability. International Journal of Computers and Applications, 25(3), 198-

205.

\section{Appendix A}

Validation findings for dimensions of the proposed model

\begin{tabular}{|c|c|c|c|c|c|c|}
\hline Dimensions of the proposed model & N & Mean & Stdev & Minimum & Maximum & Rating \\
\hline Quality of content and information & 16 & 4.38 & 0.619 & 3 & 5 & +++ \\
\hline Appropriateness of content with strategy & 16 & 4.31 & 0.602 & 3 & 5 & ++ \\
\hline Appropriateness of content with standard & 16 & 4.06 & 0.680 & 3 & 5 & + \\
\hline $\begin{array}{c}\text { Appropriateness of content with } \\
\text { instructional design }\end{array}$ & 16 & 4.50 & 0.516 & 4 & 5 & ++++ \\
\hline
\end{tabular}

Validation findings for Indicators of the proposed model

\begin{tabular}{|l|c|c|c|c|c|}
\hline Indicators of the proposed model & N & Mean & Stdev & Minimum & Maximum \\
\hline 1.Course Content & 16 & 4.50 & 0.516 & 4 & 5 \\
\hline 2.Accuracy of Content & 16 & 4.31 & 0.704 & 3 & 5 \\
\hline 3.Accessibility & 16 & 4.38 & 0.619 & 3 & 5 \\
\hline 4.Pedagogical Decontextualisation Level & 16 & 4.50 & 0.516 & 4 & 5 \\
\hline 5.Organizational Strategies & 16 & 4.25 & 0.683 & 3 & 5 \\
\hline 6.Infrastructure Support Strategies & 16 & 4.50 & 0.516 & 4 & 5 \\
\hline 7.Support Activities for Learning Goals & 16 & 4.38 & 0.619 & 43 & 5 \\
\hline 8.A Variety of Tools Enhance Interaction & 16 & 4.25 & 0.683 & 3 & 5 \\
\hline 9.Interaction Usability & 16 & 4.19 & 0.655 & 3 & 5 \\
\hline 10.Reusability & 16 & 3.75 & 0.683 & 3 & 5 \\
\hline 11.More Extensive Standards & 16 & 4.13 & 0.719 & 3 & 5 \\
\hline 12.Size of Object & 16 & 3.81 & 0.655 & 3 & 5 \\
\hline 13.Retrieval Quality & 16 & 3.94 & 0.680 & 3 & 5 \\
\hline 14.Technical Features & 16 & 4.19 & 0.750 & 3 & 5 \\
\hline 15.Presentation Design (Display) & 16 & 4.38 & 0.619 & 3 & 5 \\
\hline 16.Learning Goal Alignment & 16 & 4.25 & 0.683 & 3 & 5 \\
\hline 17.LO Architecture & 16 & 4.19 & 0.750 & 3 & 5 \\
\hline 18.Navigation & 16 & 4.19 & 0.834 & 3 & 5 \\
\hline 19. Cultural Appropriateness and & 16 & 4.13 & 0.806 & 3 & 5 \\
\hline Diversity & & & & \\
\hline 20.Conduct Needs Assessment & 16 & 4.50 & 0.516 & 4 & 5 \\
\hline 21.Conduct Task Analysis & 16 & 4.44 & 0.629 & 3 & 5 \\
\hline 22.Develop Assessment Strategies & 16 & 4.50 & 0.516 & 4 & 5 \\
\hline
\end{tabular}




\section{Appendix B}

Questionnaire survey of experts about dimensions of the proposed framework

\begin{tabular}{|c|c|c|c|c|c|}
\hline Dimensions of the proposed model & 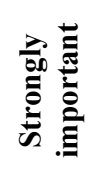 & 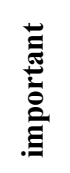 & $\frac{\overline{\tilde{E}}}{\overline{\bar{z}}}$ & 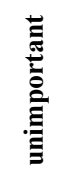 & 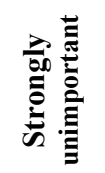 \\
\hline Quality of content and information & $\square$ & $\square$ & $\square$ & $\square$ & $\square$ \\
\hline Appropriateness of content with strategy & $\square$ & $\square$ & $\square$ & $\square$ & $\square$ \\
\hline Appropriateness of content with standard & $\square$ & $\square$ & $\square$ & $\square$ & $\square$ \\
\hline Appropriateness of content with instructional design & $\square$ & $\square$ & $\square$ & $\square$ & $\square$ \\
\hline \multicolumn{6}{|c|}{$\begin{array}{l}\text { Please mention any other dimension you feel suitable for the framework design in } \\
\text { addition to the proposed four dimensions. }\end{array}$} \\
\hline
\end{tabular}

\section{Appendix C}

Questionnaire survey of experts about criteria of the proposed framework

\begin{tabular}{|c|c|c|c|c|c|}
\hline Quality of content and information & 尊言 & 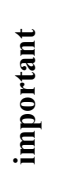 & 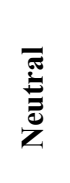 & 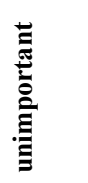 & 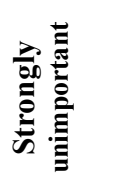 \\
\hline 1.Course Content & $\square$ & $\square$ & $\square$ & $\square$ & $\square$ \\
\hline 2.Accuracy of Content & $\square$ & $\square$ & $\square$ & $\square$ & $\square$ \\
\hline 3.Accessibility & $\square$ & $\square$ & $\square$ & $\square$ & $\square$ \\
\hline 4.Pedagogical Decontextualisation Level & $\square$ & $\square$ & $\square$ & $\square$ & $\square$ \\
\hline \multicolumn{6}{|c|}{$\begin{array}{l}\text { Do you feel that the proposed criteria are sufficient for the dimension? Please men- } \\
\text { tion any criterion you feel it has been missed. }\end{array}$} \\
\hline Appropriateness of content with strategy & 总言 & 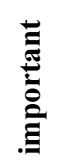 & 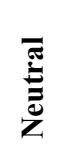 & 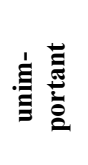 & 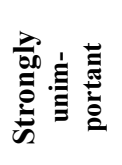 \\
\hline 5.Organizational Strategies & $\square$ & $\square$ & $\square$ & $\square$ & $\square$ \\
\hline 6.Infrastructure Support Strategies & $\square$ & $\square$ & $\square$ & $\square$ & $\square$ \\
\hline 7.Support Activities for Learning Goals & $\square$ & $\square$ & $\square$ & $\square$ & $\square$ \\
\hline
\end{tabular}




\begin{tabular}{|c|c|c|c|c|c|}
\hline 8.A Variety of Tools Enhance Interaction & $\square$ & $\square$ & $\square$ & $\square$ & $\square$ \\
\hline \multicolumn{6}{|c|}{$\begin{array}{l}\text { Do you feel that the proposed criteria are sufficient for the dimension? Please men- } \\
\text { tion any criterion you feel it has been missed. }\end{array}$} \\
\hline Appropriateness of content with standard & 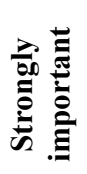 & 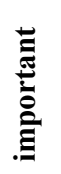 & $\begin{array}{l}\overline{\widetilde{z}} \\
\overline{\bar{z}}\end{array}$ & 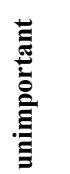 & 齐 \\
\hline 9.Interaction Usability & $\square$ & $\square$ & $\square$ & $\square$ & $\square$ \\
\hline 10.Reusability & $\square$ & $\square$ & $\square$ & $\square$ & $\square$ \\
\hline 11.More Extensive Standards & $\square$ & $\square$ & $\square$ & $\square$ & $\square$ \\
\hline 12.Size of Object & $\square$ & $\square$ & $\square$ & $\square$ & $\square$ \\
\hline 13.Retrieval Quality & $\square$ & $\square$ & $\square$ & $\square$ & $\square$ \\
\hline 14.Technical Features & $\square$ & $\square$ & $\square$ & $\square$ & $\square$ \\
\hline
\end{tabular}

Do you feel that the proposed criteria are sufficient for the dimension? Please mention any criterion you feel it has been missed.

\begin{tabular}{|c|c|c|c|c|c|}
\hline $\begin{array}{l}\text { Appropriateness of content with instructional de- } \\
\text { sign }\end{array}$ & 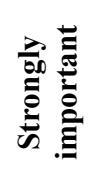 & 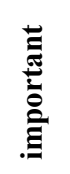 & $\overline{\underline{\underline{\Sigma}}}$ & 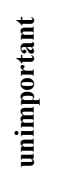 & 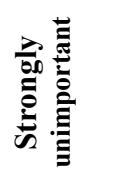 \\
\hline 15.Presentation Design (Display) & $\square$ & $\square$ & $\square$ & $\square$ & $\square$ \\
\hline 16.Learning Goal Alignment & $\square$ & $\square$ & $\square$ & $\square$ & $\square$ \\
\hline 17.LO Architecture & $\square$ & $\square$ & $\square$ & $\square$ & $\square$ \\
\hline 18.Navigation & $\square$ & $\square$ & $\square$ & $\square$ & $\square$ \\
\hline 19. Cultural Appropriateness and Diversity & $\square$ & $\square$ & $\square$ & $\square$ & $\square$ \\
\hline 20.Conduct Needs Assessment & $\square$ & $\square$ & $\square$ & $\square$ & $\square$ \\
\hline 21.Conduct Task Analysis & $\square$ & $\square$ & $\square$ & $\square$ & $\square$ \\
\hline 22.Develop Assessment Strategies & $\square$ & $\square$ & $\square$ & $\square$ & $\square$ \\
\hline \multicolumn{6}{|c|}{$\begin{array}{l}\text { Do you feel that the proposed criteria are sufficient for the dimension? Please mention any criteri- } \\
\text { on you feel it has been missed. }\end{array}$} \\
\hline \multicolumn{6}{|c|}{$\begin{array}{l}\text { Please mention any other dimension you feel suitable for the framework design in additior } \\
\text { to the proposed four dimensions. }\end{array}$} \\
\hline
\end{tabular}




\section{Biographies}

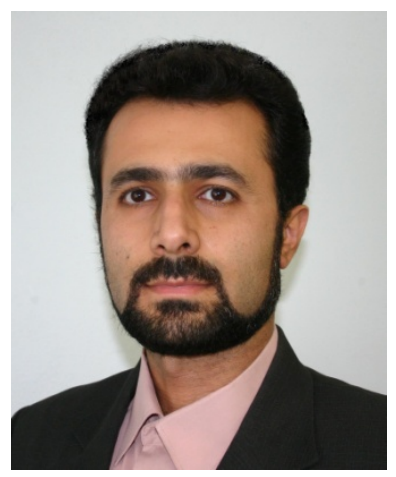

Peyman Akhavan received his M.Sc. and Ph.D. degrees in industrial engineering from Iran University of Science and Technology, Tehran, Iran. His research interests are in knowledge management, information technology, innovation and strategic planning. He has published 6 books and has more than 100 research papers in different conferences and journals. Peyman Akhavan is corresponding author of this paper and can be contacted at: akhavan@iust.ac.ir

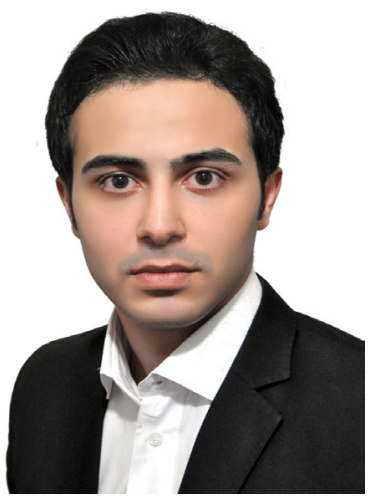

Majid Feyz Arefi received his B.Sc. degree in Pure Mathematic from Ferdowsi University of Mashhad, Iran in 2008. He received his M.Sc. degree in Industrial Engineering with specialty in System Management and Productivity from Malek-Ashtar University of Technology, Tehran, Iran in 2012. During his studies he has been working on topics such as: E-learning, Learning Objects, Information Technology, Customer Satisfaction and After-Sales Services. His fields of interests include E-learning, E-content and Co-creation. He is currently continuing his research with Dr. Akhavan. (majidfeyzarefi@gmail.com) 